\title{
Handwashing and antiseptic-containing soaps in hospital
}

\author{
J. D. JARVIS, C. D. WYNNE 1 , L. ENWRIGHT ${ }^{2}$, AND J. D. WILLIAMS \\ From the Department of Medical Microbiology, The London Hospital, UK
}

SUMMARY Two aspects of handwashing in hospital were considered. A study was carried out to examine the contamination of bar soap and containers, and the use of antiseptic soaps in reducing the resident flora of the skin. Swabs were collected from soap dishes on six wards and from a bacteriology laboratory on four consecutive days. The unmedicated bar soap was replaced by bar soap containing $2.5 \%$ povidone-iodine, and further swabs were collected over a period of seven days. Ninety-two isolates from 48 samples were obtained when unmedicated bar soap was used, and nine isolates from 42 samples when povidone-iodine (Betadine) soap was substituted. The number of organisms recovered when povidone-iodine soap was used was much reduced, and Pseudomonas spp were recovered in low numbers on only one occasion.

Six laboratory workers took part in a study to compare bar soap with other agents-povidoneiodine soap, povidone-iodine surgical scrub, povidone-iodine alcoholic solution, chlorhexidine surgical scrub, and alcoholic chlorhexidine. Samples were collected after standard washes and after surgical gloves had been worn for 90 minutes. The effect of multiple washes was assessed by samples collected after six washes with the agent under study (three per day) followed by 90 minutes wearing surgical gloves. The average percentage reduction in normal flora obtained indicated that alcoholic chlorhexidine was superior to the other agents.

The spread of infection in hospital can occur by many different routes, including the air and fomites, but it is commonly accepted that the main mechanism for the transfer of organisms is by direct contact, and the main vehicle is the hands of the attendant (Ehrenkranz, 1971). The organisms present on the hands comprise the resident bacterial flora, including micrococci and diphtheroid bacilli (Lowbury and Lilly, 1960) and transient organisms including staphylococci and Gram-negative rods, which are picked up from environmental and human sources in hospital and survive for short periods on the skin (Bruun and Solberg, 1973). If there is damage to the hands after minor trauma or some pathological process, transient, potentially pathogenic organisms may become established in the lesion and persist for longer periods.

Effective handwashing is probably the single most important means of reducing hospital-acquired

1Present address: Westminster Hospital, London SW1
2Present address: Whittington Hospital, London N19

Received for publication 2 January 1979 infection (Colbeck, 1962; Top, 1967). For some purposes, for example, to prevent self or crossinfection after handling infected sites, it is necessary to remove transient pathogenic organisms from the hands, whereas in other circumstances, for example, before surgical operations, injections, and venepuncture, it may be necessary to reduce the resident flora in addition to removing transient organisms. There is some difference of opinion as to which situations require the use of germicides or antiseptics, with or without scrubbing of the hands, and which require only simple handwashing with unmedicated soaps.

The problems that may arise in such a simple procedure as handwashing may lead to worsening of cross-infection problems, including washing the hands with contaminated soap solutions (Anderson, 1962), drying the hands on moist, contaminated, communal towels (Rowland and Alder, 1972), or smearing on to the hands emollient creams containing bacteria (Morse et al., 1967).

This report describes studies on the contamination of bar soap and containers in hospital and on the use of antiseptic soaps in reducing resident flora of the skin. 


\section{Contamination of soap dishes}

Bar soap without antiseptics is commonly used in hospital for routine handwashing on wards and in staff areas. The receptacles used to hold the tablet of soap frequently contain sludge, which surrounds the soap and contaminates it with organisms surviving and growing in the sludge. The organisms are predominantly Gram-negative rods, such as Pseudomonas aeruginosa and Klebsiella or Proteus species but Staphylococcus aureus may also occur. The communal use of sinks and the absence of clear lines of responsibility for maintaining domestic cleaning in many wards may lead to irregular cleaning of soap receptacles. Efforts to avoid these problems include the provision of liquid soap dispensers, often containing antiseptics, the use of dispensers of powdered dry soap, or the use of individual thin flakes of soap for washing. It is common, however, to find the containers empty, not working, leaking, or with the nozzle caked with dried liquid soap. Despite the advanced technology seen in modern hospitals, there appears to be no reliable substitute for bar soap. In this study we looked at the bacterial flora of bar soap containers in hospital and the effect of adding an iodophor to the bar soap.

\section{Methods}

Swabs were collected from soap dishes in 11 sites on six wards and from one site in a bacteriology laboratory over four consecutive days. At the end of this time the unmedicated bar soap was replaced by bar soap containing $2.5 \%$ povidone-iodine (Betadine) soap. Further swabs were collected from the sites over a seven-day period. The swabs were placed in sterile $1 \%$ Tween 80 neutraliser for 5 minutes before plating out onto blood agar and MacConkey agar plates, which were then incubated aerobically at $37^{\circ} \mathrm{C}$ for 24 hours.

A similar experiment was carried out on three soap dishes from three wards and on one dish from a bacteriology laboratory over seven consecutive

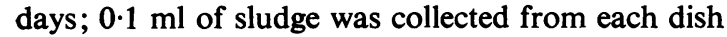
and diluted for quantitative bacterial counts on MacConkey agar. The bar soap was replaced by Betadine-containing soap, and quantitative counts were carried out for a further four days.

\section{REMOVAL OF ORGANISMS FROM THE HANDS}

Several established agents used for hand disinfection were compared with bar soaps. The agents used were:

povidone-iodine surgical scrub (Betadine)

chlorhexidine surgical scrub (Hibiscrub)

$95 \%$ alcohol with $0.5 \%$ chlorhexidine and $0.1 \%$ glycerol alcoholic povidone-iodine solution (alcoholic Betadine solution)

in comparison with the use of plain bar soap and Betadine bar soap.

Six laboratory workers, four men and two women, took part in the study. There was no history of past skin disease, and no skin infection or other lesion was present during the study period. The hands were washed with one agent for a period of 2 minutes.

Liquid agents were dispensed in $10 \mathrm{ml}$ aliquots and two were used for each wash. The alcoholic agents were allowed to evaporate from the hands after vigorous rubbing, and after washing with the aqueous detergent solutions, the hands were dried with a sterile towel. Samples were then collected for culture. Each subject was allocated a different sequence of antiseptic agents, and the gap between experiments with a new agent was at least 10 days.

In order to simulate operating theatre methods, sterile surgical gloves were worn for 90 minutes after washing, and during this period normal daily duties were undertaken. Gloves were then removed and further samples were collected.

Specimens for culture were obtained by rinsing the hands in quarter-strength Ringer's solution for a measured time of 30 seconds. Neutralisation of residual antiseptic was effected by inclusion in the Ringer's solution, and in the pour plates, of the following neutralisers:

$1 \%$ Lubrol W, $0.5 \%$ lecithin, $1 \%$ Tween 80 , and $1 \%$ sodium thiosulphate.

Pour plates were made from the washings and, after incubation for 48 hours at $37^{\circ} \mathrm{C}$, colony counts were made.

The effects of multiple washings were assessed by washing the hands three times a day with the agent under study. Specimens for culture were collected after the sixth wash. Gloves were again worn for 90 minutes and specimens were collected for culture.

\section{Results}

The results of the cultures from the sludge in soap dishes are shown in the Figure. The organisms isolated from soap dishes containing plain bar soap are shown on the first four days and from dishes containing Betadine soap on the fifth to ninth days. Over the three-day period, all 12 dishes showed contamination, and on only five occasions were sterile cultures obtained. After substitution of Betadine bar soap, only one positive culture was obtained from the 12 dishes during the next four days, but on subsequent days, contaminating organisms made their appearance. Table 1 shows the results of cultures from bar soap dishes compared with cultures from dishes containing Betadine bar 


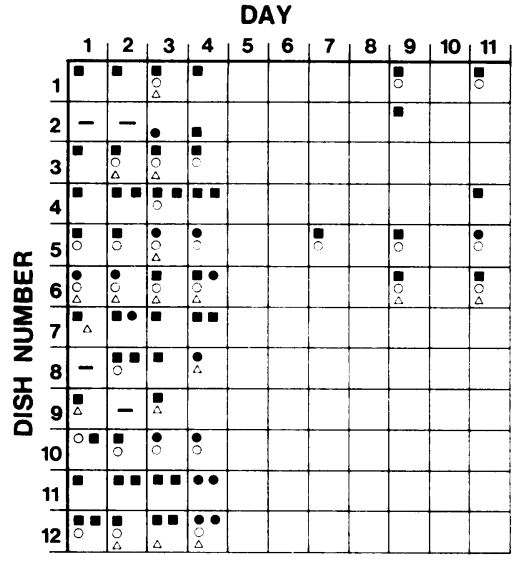

Figure Organisms isolated from soap dishes containing plain bar soap from day 1 to day 4 inclusive and povidone-iodine soap thereafter: $\square$ pseudomonas; $\triangle$ klebsiella; $\bigcirc$ coliform; $\bigcirc$ serratia.

Table 1 Comparison of isolates from plain bar soap and Betadine soap

\begin{tabular}{lrc}
\hline & Bar soap & Betadine soap \\
\hline Number of samples & 48 & 42 \\
Number with no growth & 5 & 33 \\
Number containing bacteria & 43 & 9 \\
Isolates of strains of & 54 & \\
$\quad$ Pseudomonas & 20 & 9 \\
Escherichia coli & 17 & 7 \\
Klebsiella spp & 1 & - \\
Serratia & 92 & 18 \\
Total isolates & & \\
\hline
\end{tabular}

soap. The number of positive cultures was $43 / 48$ $(90 \%)$ with bar soap, falling to $9 / 42(20 \%)$ with Betadine soap. Ninety-two isolates were obtained from plain soap compared to 18 from the Betadine soap dishes.

In Table 2 the results of viable bacterial counts are recorded. During this series of tests, the Betadine dishes grew Pseudomonas on only one occasion at the low concentration of less than 100 organisms per millilitre. Bacteria from plain soap dishes were obtained on all but two occasions. The dishes contained numbers of bacteria which were sometimes in the range of 100 per $\mathrm{ml}$, but usually more than 1000000 organisms per $\mathrm{ml}$ were recovered. As can be seen from the Figure and Table 1, the organisms present in the dishes varied from day to day, indicating frequent replacement of one bacterial strain by another.

Differences between the yield of bacteria from skin after washing and after treatment with various antiseptic preparations are shown in Table 3. Compared to the counts obtained by the use of plain bar soap, Betadine bar soap achieved a reduction of resident flora ranging from 27 to $95 \%$; the total numbers of organisms were very high in three subjects (4050-7700). Betadine scrub was more effective in that lower yields of skin bacteria were obtained than after using ordinary soap, and in four out of five subjects the flora were reduced by more than $90 \%$. With chlorhexidine scrub, three out of six subjects had a $90 \%$ or more reduction of flora. With alcohol and chlorhexidine, the reduction in flora was

Table 2 Bacterial counts in organisms per ml from four soap dishes over a period of 11 days: Plain bar soap used for first seven days and Betadine over succeeding four days

\begin{tabular}{|c|c|c|c|c|}
\hline \multirow[t]{2}{*}{ Day } & \multicolumn{4}{|l|}{ Dish number } \\
\hline & 1 & 2 & 3 & 4 \\
\hline 1 & Pseudomonas sp $1 \times 10^{4}$ & Pseudomonas sp $1 \times 10^{2}$ & Pseudomonas sp $1 \times 10^{4}$ & Klebsiella sp $1 \times 10^{4}$ \\
\hline & Coli $1 \times 10^{4}$ & 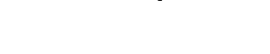 & $1 \times 10^{4}$ & $\begin{array}{ll}\text { Coli } & 1 \times 10^{3} \\
\text { Pseudomonas sp } 1 \times 10^{5}\end{array}$ \\
\hline 2 & Pseudomonas sp $1 \times 10^{6}$ & 0 & 0 & $\begin{array}{l}\text { Pseudomonas sp } 11 \times 10^{6} \\
\text { Pseudomonas sp } 21 \times 10^{6}\end{array}$ \\
\hline 3 & Pseudomonas sp $1 \times 10^{4}$ & Pseudomonas sp $1 \times 10^{2}$ & Pseudomonas sp $1 \times 10^{6}$ & $\begin{array}{l}\text { Klebsiella sp } 1 \times 10^{3} \\
\text { Pseudomonas sp } 1 \times 10^{6} \\
\text { Klebsiella } \text { sp }\end{array}$ \\
\hline 4 & $\begin{array}{l}\text { Pseudomonas sp } 11 \times 10^{5} \\
\text { Pseudomonas sp } 21 \times 10^{5}\end{array}$ & Pseudomonas sp $1 \times 10^{2}$ & $\begin{array}{ll}\text { Pseudomonas sp } & 1 \times 10^{6} \\
\text { Klebsiella sp } & 1 \times 10^{4}\end{array}$ & $\begin{array}{l}\text { Coli sp } \\
\text { NT }\end{array}$ \\
\hline 5 & Pseudomonas sp $11 \times 10^{8}$ & Pseudomonas sp $1 \times 10^{3}$ & $\begin{array}{l}\text { Pseudomonas sp } 11 \times 10^{5} \\
\text { Pseudomonas sp } 21 \times 10^{6}\end{array}$ & NT \\
\hline 6 & $\begin{array}{l}\text { Pseudomonas sp } 11 \times 10^{6} \\
\text { Pseudomonas sp } 21 \times 10^{6}\end{array}$ & Pseudomonas sp $1 \times 10^{2}$ & $\begin{array}{l}\text { Pseudomonas sp } 11 \times 10^{6} \\
\text { Pseudomonas sp } 21 \times 10^{6}\end{array}$ & NT \\
\hline 7 & $\begin{array}{ll}\text { Pseudomonas sp } 11 \times 10^{6} \\
\text { Pseudomonas sp } 21 \times 10^{6} \\
\text { Klebsiella sp } & 1 \times 10^{3}\end{array}$ & Pseudomonas sp $1 \times 10^{3}$ & Pseudomonas sp $11 \times 10^{5}$ & NT \\
\hline 8 & 0 & 0 & Pseudomonas sp $11 \times 10^{2}$ & 0 \\
\hline 9 & 0 & 0 & 0 & 0 \\
\hline 10 & 0 & 0 & 0 & 0 \\
\hline 11 & 0 & 0 & 0 & 0 \\
\hline
\end{tabular}

NT $=$ not tested 
Table 3 Bacterial counts of residual flora immediately after hand washing

\begin{tabular}{|c|c|c|c|c|c|c|}
\hline \multirow[t]{2}{*}{ Washing agent } & \multicolumn{6}{|l|}{ Subject } \\
\hline & $1 M$ & $2 M$ & $3 M$ & $4 M$ & $5 F$ & $6 F$ \\
\hline Bar soap & 10500 & 1890 & 8600 & 9500 & 865 & 2070 \\
\hline Povidone-iodine & 7700 & 555 & 4050 & 1750 & 42 & 6800 \\
\hline (B ztadine) soap & (27) & (71) & (53) & (82) & (95) & (nil) \\
\hline Povidone-iodine & 5400 & 22 & 71 & - & 69 & 63 \\
\hline (Betadine) surgical scrub & (48) & (99) & (99) & - & (92) & (97) \\
\hline Chlorhexidine & 18 & 3300 & 860 & 5800 & 51 & 1080 \\
\hline scrub & (99.9) & (nil) & (90) & (39) & $(94)$ & (49) \\
\hline Alcohol and & 11 & 72 & $<1$ & $<1$ & 600 & $<1$ \\
\hline chlorhexidine & $(99.9)$ & (96) & $(99.9)$ & $(99 \cdot 9)$ & (31) & $(99.9)$ \\
\hline Alcoholic povidone-iodine & 150 & 15 & 17 & 440 & - & 330 \\
\hline solution (Betadine) & $(98 \cdot 5)$ & $(99 \cdot 2)$ & $(99 \cdot 8)$ & $(95 \cdot 4)$ & - & $(83.9)$ \\
\hline
\end{tabular}

Results are expressed in organisms per ml. The percentage given in parentheses means percentage less than counts after a soap-and-water wash.

$\mathbf{M}=$ male $; \quad F=$ female

very marked, and very few organisms were recovered from the washings from five of the six subjects. Using Betadine alcoholic solution, 4 out of 5 had a reduction of $95 \%$ or more.

Table 4 shows that results similar to those from the first wash were obtained after the sixth wash with the antiseptic agents. Some variation in susceptibility of the normal flora was shown in the results from different subjects. The flora in subjects 1 and 6 were more resistant to removal by Betadine than by chlorhexidine. In all subjects save one, alcohol and chlorhexidine produced the largest reduction in normal flora.

Table 5 shows the bacterial counts after gloves had been worn for a 90-minute period. Counts of over 500 organisms were obtained from three subjects after Betadine soap and Betadine alcoholic solution, from one (out of five) after Betadine scrub, from four after chlorhexidine scrub, but from none after alcoholic chlorhexidine.

Table 6 shows the average percentage reduction in normal flora obtained by the six subjects using the five antiseptic agents. Alcoholic chlorhexidine was clearly superior to the other agents.

\section{Discussion}

Handwashing is such an important part of the control of infection measures that it requires careful attention. The purposes for which handwashing is performed in hospital are:

1 Removal of transient pathogenic organisms before carrying out manipulative procedures on patients The degree to which this process must be pursued depends on the procedure to be carried out. For many ward tasks of a domestic nature, for example, bed making, provision of meals, and for nursing and medical tasks such as temperature recording and clinical examination, social cleanliness is all that is necessary; this can be achieved with unmedicated bar soap. Procedures on patients with normal defence mechanisms where careful aseptic techniques are applied, for example, blood taking and parenteral injection, may also be safely performed after social cleaning, but complex procedures such as lumbar puncture or manipulations in immunosuppressed patients require more exacting measures. 2 Decontamination of hands after procedures liable to cause contamination Procedures such as removal of

Table 4 Bacterial counts of residual flora of hands after six washes with each agent spread over two-day period: Each agent was used in turn with a 10-day interval between washes

\begin{tabular}{|c|c|c|c|c|c|c|}
\hline \multirow[t]{2}{*}{ Washing agent } & \multicolumn{6}{|l|}{ Subject } \\
\hline & $I$ & 2 & 3 & 4 & 5 & 6 \\
\hline Bar soap & 10550 & 1890 & 8600 & 9500 & 865 & 2070 \\
\hline $\begin{array}{l}\text { Povidone-iodine } \\
\text { (Betadine) soap }\end{array}$ & $\begin{array}{r}4140 \\
(67)\end{array}$ & $\begin{array}{r}760 \\
(60)\end{array}$ & $\begin{array}{r}260 \\
(97)\end{array}$ & $\begin{array}{r}6500 \\
(32)\end{array}$ & $\begin{array}{r}52 \\
(94)\end{array}$ & $\begin{array}{r}14900 \\
\text { (nil) }\end{array}$ \\
\hline $\begin{array}{l}\text { Povidone-iodine } \\
\text { (Betadine) surgical scrub }\end{array}$ & $\begin{array}{r}280 \\
(97)\end{array}$ & $\begin{array}{r}133 \\
(93)\end{array}$ & $\begin{array}{r}2 \\
(99.9)\end{array}$ & - & $\begin{array}{r}305 \\
(65)\end{array}$ & $\begin{array}{l}540 \\
(74)\end{array}$ \\
\hline Chlorhexidine scrub & $\begin{array}{r}21 \\
(99.9)\end{array}$ & $\begin{array}{l}500 \\
(74)\end{array}$ & $\begin{array}{r}12 \\
(99 \cdot 8)\end{array}$ & $\begin{array}{r}1545 \\
(84)\end{array}$ & $\begin{array}{l}515 \\
(40)\end{array}$ & $\begin{array}{l}600 \\
(71)\end{array}$ \\
\hline $\begin{array}{l}\text { Alcohol and } \\
\text { chlorhexidine }\end{array}$ & $\begin{array}{r}4 \\
(99 \cdot 9)\end{array}$ & $\begin{array}{r}94 \\
(95)\end{array}$ & $\begin{array}{r}21 \\
(99 \cdot 9)\end{array}$ & $\begin{array}{r}2 \\
(99)\end{array}$ & $\begin{array}{r}60 \\
(93)\end{array}$ & $\begin{array}{r}21 \\
(99 \cdot 9)\end{array}$ \\
\hline $\begin{array}{l}\text { Alcoholic povidone-iodine } \\
\text { solution (Betadine) }\end{array}$ & $\begin{array}{r}31 \\
(99 \cdot 7)\end{array}$ & $\begin{array}{r}2 \\
(99 \cdot 9)\end{array}$ & $\begin{array}{r}270 \\
(96 \cdot 4)\end{array}$ & $\begin{array}{r}788 \\
(91 \cdot 7)\end{array}$ & - & $\begin{array}{l}430 \\
(79)\end{array}$ \\
\hline
\end{tabular}


Table 5 Bacterial counts of skin flora after washing with antibacterial agents and wearing gloves for a 90-minute period

\begin{tabular}{|c|c|c|c|c|c|c|}
\hline \multirow[t]{2}{*}{ Washing agent } & \multicolumn{6}{|l|}{ Subject } \\
\hline & 1 & 2 & 3 & 4 & 5 & 6 \\
\hline Bar soap & 22500 & 185 & 2500 & 6900 & 852 & 2265 \\
\hline Povidone-iodine & 7500 & 5 & 385 & 610 & 52 & 19000 \\
\hline (Betadine) soap & $(66)$ & (97) & (85) & (91) & (94) & (nil) \\
\hline $\begin{array}{l}\text { Povidone-iodine } \\
\text { (Betadine) scrub }\end{array}$ & 6600 & $\begin{array}{r}18 \\
(90)\end{array}$ & 36 & - & 305 & 36 \\
\hline \multirow[t]{2}{*}{ Chlorhexidine scrub } & $\begin{array}{r}(70) \\
10\end{array}$ & $\begin{array}{r}(90) \\
1600\end{array}$ & $\begin{array}{l}(99) \\
170\end{array}$ & $11 \overline{500}$ & $\begin{array}{l}(65) \\
575\end{array}$ & $\begin{array}{r}(98) \\
500\end{array}$ \\
\hline & $(99.9)$ & (nil) & (94) & (nil) & (40) & (78) \\
\hline $\begin{array}{l}\text { Alcohol and } \\
\text { chlorhexidine }\end{array}$ & 20 & 12 & 21 & 200 & 60 & 21 \\
\hline chlorhexidine & $(99 \cdot 9)$ & (94) & $(99 \cdot 9)$ & (97) & (93) & (99) \\
\hline \multirow{2}{*}{$\begin{array}{l}\text { Alcoholic povidone-iodine } \\
\text { solution (Betadine) }\end{array}$} & 1800 & & 25 & 2400 & - & 680 \\
\hline & $(92 \cdot 0)$ & $(99 \cdot 1)$ & $(99 \cdot 3)$ & (64) & - & (70) \\
\hline
\end{tabular}

Table 6 Average percentage reduction in normal flora after antiseptic washes

\begin{tabular}{lll}
\hline & After 1 wash & After 6th wash \\
\hline $\begin{array}{l}\text { Povidone-iodine } \\
\text { (Betadine) soap }\end{array}$ & 65 & 68 \\
$\begin{array}{l}\text { Povidone-iodine } \\
\text { (Bztadine) scrub }\end{array}$ & 87 & 85 \\
Chlorhexidine scrub & 74 & 77 \\
Alcoholic chlorhexidine & 96 & 98 \\
Alcoholic povidone-iodine solution & 95 & 93 \\
(Betadine) & & \\
\hline
\end{tabular}

infected dressings, collection of sputum containers, emptying bedpans, attending to tracheostomy suction, or handling plastic bags used for urinary bladder drainage may require more than social cleaning. This aspect has not been studied in this present series, but earlier reports suggest that plain bar soap will remove the majority of contaminating organisms from the hands by mechanical means (Lowbury et al., 1974). In areas where highly susceptible patients are housed, such as burns units, transplant units, intensive care units, premature baby units, and neurosurgical wards, there may be justification for the wider use of antiseptic soaps, particularly in view of recent reports of Klebsiella being carried on the hands in such centres (Casewell and Phillips, 1977). In maternity units, hexachlorophane has been used for many years to reduce the carriage of staphylococci on the hands.

3 Removal of most of the normal flora and its suppression during the performance of complex manipulations on patients such as surgical operations The studies outlined above show that alcoholic chlorhexidine is an effective agent for this purpose. The studies with this compound confirm the findings of Lowbury et al. (1974).

In addition to the objectives in washing the hands, one must also consider the hazards of contamination acquired from materials used in cleaning the hands, which may arise and lead to an increase rather than decrease of infection. Two types of problem require particular attention:

1 Bacterial contamination may occur in materials 우 used to wash the hands. There have been numerous reports of infected disinfectants from hospitals (Dulake and Kidd, 1966; Mitchell, 1966; Parker, 1972; Basset, 1971), and those used to wash the $\vec{\varphi}$ hands are not excepted. The present study indicates 0 that soap dishes are frequently contaminated. Although much of the contaminated sludge from the dish which gets onto the hands when picking up the soap may be removed under running water, the sludge is a potentially hazardous source of contamination on the ward. The number of infected soap dishes was greatly reduced by the use of Betadine soap, although after four days' use, contaminated sludge began to appear again.

2 Contamination may occur in material used to dry the hands. The use of communal linen towels has long been recognised to be an important vector for the transmission of Gram-negative pathogens, and efforts have been made to eliminate their use. Paper towels are gradually replacing linen towels in hospitals, although some education in their use is still necessary.

We acknowledge the help of Miss P. Lowe, Dudley $\stackrel{N}{\circ}$ Road Hospital, Birmingham 18, for assistance in $N$ part of this study.

\section{References}

Anderson, K. (1962). The contamination of hexa-? chlorophene soap with Pseudomonas pyocyanea. Medical Journal of Australia, 49, 463-465.

Basset, D. J. C. (1971). Common-source outbreaks. Proceedings of the Royal Society of Medicine, 64,

980-986.
Bruun, J. N., and Solberg, C. O. (1973). Hand carriage of Gram-negative bacilli and Staphylococcus aureus. British Medical Journal, 2, 580-582. 
Casewell, M. W., and Phillips, I. (1977). Hands as route of transmission for Klebsiella species. British Medical Journal, 2, 1315-1317.

Colbeck, J. C. (1962). Control of Infections in Hospitals. American Hospital Association, Chicago.

Dulake, C., and Kidd, E. (1966). Contaminated irrigating fluid (Letter). Lancet, 1, 980.

Ehrenkranz, N. J. (1971). Hospital infection-an overview. Paper presented to a Symposium on Antiseptic Techniques to Prevent the Development and Spread of Infection. University of Miami School of Medicine, Key Biscayne, Florida.

Lowbury, E. J. L., and Lilly, H. A. (1960). Disinfection of the hands of surgeons and nurses. British Medical Journal, 1, 1445-1450.

Lowbury, E. J. L., Lilly, H. A., and Ayliffe, G. A. J. (1974). Preoperative disinfection of surgeons' hands: use of alcoholic solutions and effects of gloves on skin flora. British Medical Journal, 4, 369-372.

Mitchell, R. G. (1966). Postoperative urinary-tract infections caused by contaminated irrigating fluid. Lancet, 1, 793-795.
Morse, L. J., Williams, H. L., Green, F. P., Eldridge, E. E., Jr., and Rotta, J. R. (1967). Septicemia due to Klebsiella pneumoniae originating from a hand-cream dispenser. New England Journal of Medicine, 277, 472-473.

Parker, M. T. (1972). The clinical significance of the presence of micro-organisms in pharmaceutical and cosmetic preparations. Journal of the Society of Cosmetic Chemists, 23, 415-426.

Rowland, A. J., and Alder, W. F. (1972). Transmission of infection through towels. Community Medicine, 128, 71-73.

Top, F. H., ed. (1967). Technics required to be followed by Hospital Personnel. In Control of Infectious Diseases in General Hospitals, Chapter 8. American Public Health Association, New York.

Requests for reprints to: Professor J. D. Williams, Department of Medical Microbiology, The London Hospital Medical College,Turner Street, London E1 2AD, UK. 